\title{
CARACTERIZACIÓN EPIDEMIOLÓGICA DE LOS CASOS DE SÍFILIS CONGÉNITA EN EL NORTE DE BRASIL, DE 2014 A 2019
}

\section{ARTÍ́CULO ORIGINAL}

ALMEIDA, Carolina Gomes ${ }^{1}$, ÁVILA, Gabriel Pereira², TEIXEIRA, Isabelly Montenegro $^{3}$, RODRIGUES, Raíza Júlia Viana ${ }^{4}$, DIAS, Claudio Alberto Gellis de Mattos $^{5}$, OLIVEIRA, Euzébio de ${ }^{6}$, DENDASCK, Carla Viana ${ }^{7}$, ARAÚJO, Maria Helena Mendonça de ${ }^{8}$, FECURY, Amanda Alves ${ }^{9}$

\section{ALMEIDA, Carolina Gomes. Et al. Caracterización epidemiológica de los casos de} sífilis congénita en el norte de Brasil, de 2014 a 2019. Revista Científica Multidisciplinar Núcleo do Conhecimento. Año 05, Ed. 12, Vol. 14, págs. 20 a 31. Diciembre de 2020. ISSN: 2448-0959, Enlace de acceso: https://www.nucleodoconhecimento.com.br/salud/norte-de-brasil, DOI: 10.32749/nucleodoconhecimento.com.br/salud/norte-de-brasil

\section{RESUMEN}

La sífilis es una enfermedad causada por la bacteria Treponema pallidum, adquirida, en gran parte, por transmisión sexual. La sífilis congénita es una enfermedad

\footnotetext{
${ }^{1}$ Académico del curso de Medicina de la Universidad Federal de Pará (UNIFAP).

${ }^{2}$ Académico del curso de Medicina de la Universidad Federal de Pará (UNIFAP).

${ }^{3}$ Académico del curso de Medicina de la Universidad Federal de Pará (UNIFAP).

${ }^{4}$ Académico del curso de Medicina de la Universidad Federal de Pará (UNIFAP).

${ }^{5}$ Doctor en Teoría e Investigación del Comportamiento (UFPA). Profesor e Investigador del Instituto Federal de Amapá (FIPA), campus Macapá, AP. Profesor e Investigador en el Programa de Posgrado en Educación Profesional y Tecnológica (ProfEPT), IFAP, campus Santana.

${ }^{6}$ Doctor en Enfermedades Tropicales (UFPA). Profesor e Investigador de la Universidad Federal de Pará (UFPA), Campus Castanhal, PA.

${ }^{7}$ Teólogo, Doctor en Psicoanálisis Clínica. Ha estado trabajando durante 15 años con Metodología Científica (Método de Investigación) en la Guía de Producción Científica de estudiantes de Maestría y Doctorado. Especialista en Investigación de Mercado e Investigación centrado en la salud. Estudiante de doctorado en Comunicación y Semiótica (PUC SP).

${ }^{8}$ Máster en Docencia y Ciencias de la Salud. Profesor e investigador de la Universidad Federal de Amapá (UNIFAP), campus Macapá, AP.

${ }^{9}$ Doctor en Enfermedades Tropicales (UFPA). Profesor e investigador de la Universidad Federal de Amapá (UNIFAP), campus Macapá. Profesor e investigador en el Programa de Posgrado en Ciencias de la Salud (UFPA). Prorrector de Investigación y Estudios de Posgrado de la Universidad Federal de Amapá (UNIFAP).

$\mathrm{RC}: 96424$

Enlace de acceso: https://www.nucleodoconhecimento.com.br/salud/norte-de-brasil
} 
contagiosa de transmisión vertical (de la madre al feto). Este estudio tuvo como objetivo presentar el número de casos reportados de sífilis congénita en el norte de Brasil, entre 2014 y 2019, y caracterizar el perfil epidemiológico de los casos. Se realizó investigación descriptiva, transversal y retrospectiva utilizando la base de datos DATASUS. Hubo un aumento en el número de casos en el período evaluado, especialmente el Estado de Amazonas, que presentó el mayor número de notificaciones. En cuanto a la atención prenatal, un promedio de cuatro veces más mujeres se desempeñan que las que no lo hicieron. Las mujeres con grado escolar materno del $5^{\circ}$ al $8^{\circ}$ grado de la escuela primaria incompleta tuvieron un mayor número de casos de la enfermedad. Aunque la región norte tuvo un alto rendimiento prenatal, la mayoría de los casos de sífilis congénita se diagnosticaron solo después del parto, lo que indica interpretaciones erróneas con respecto a las pruebas y el consiguiente error en el diagnóstico y el tratamiento. Dado que la forma temprana (emergencia hasta el $2^{\circ}$ año de vida) es la mayoría del número de casos, hay una evolución favorable de la enfermedad. La escolarización y los ingresos parecen ser factores que influyen en el diagnóstico tardío de la enfermedad. Existe la necesidad de aumentar las parejas tratadas, reduciendo la transmisión de la sífilis y, en consecuencia, la sífilis congénita.

Palabras clave: Sífilis congénita, Región Norte, Prenatal.

\section{INTRODUCCIÓN}

La sífilis es una infección bacteriana sistémica, crónica, curable y exclusiva del ser humano. Cuando no se trata, evoluciona a etapas de gravedad variable y puede afectar órganos y sistemas del cuerpo (BRASIL, 2018). El agente causal de la sífilis es la bacteria Treponema pallidum, una espiroqueta, adquirida en la mayoría de los casos durante las relaciones sexuales. La enfermedad se clasifica, según sus diferentes vías de transmisión, en sífilis adquirida y sífilis congénita (CAVALCANTE et al., 2012, ROCHA et al., 2020).

La sífilis congénita es el resultado de la propagación hematógena de T. pallidum, de la mujer embarazada infectada que no recibe tratamiento o tratamiento inadecuado RC: 96424

Enlace de acceso: https://www.nucleodoconhecimento.com.br/salud/norte-de-brasil 
para su conceptus, transplacentario (CRT, 2016). La transmisión puede ocurrir durante todo el embarazo, y el riesgo es mayor en mujeres embarazadas con sífilis primaria o secundaria (GUINSBURG; SANTOS, 2010, BARROS et al., 2020).

Es una enfermedad responsable de aproximadamente el $40 \%$ de las tasas de mortalidad perinatal, el $25 \%$ de la muerte fetal, el $14 \%$ de las muertes neonatales (CARDOSO et al., 2018). Además, es capaz de conllevar graves consecuencias para el conceptus como complicaciones sistémicas, ya sea en la sífilis congénita temprana (afectación ósea, neurológica, hematológica y hepatoesplénica), o tardía (estigmas derivados de la remodelación y deformidades óseas) (MOTTA et al., 2018).

El control efectivo de la sífilis tiene como premisa fundamental el cribado serológico y el tratamiento adecuado de las mujeres embarazadas y parejas sexuales, ya que la calidad de la atención prenatal y del parto es un determinante importante en la reducción de la transmisión vertical. La penicilina es el fármaco de elección en el tratamiento de la sífilis y el único indicado para mujeres embarazadas: tiene una eficacia del $98 \%$ en la prevención de la sífilis congénita, actuando en todas las etapas de la enfermedad (CAVALCANTE; PEREIRA CASTRO, 2017).

\section{GOL}

Presentar el número de casos reportados de sífilis congénita en el norte de Brasil, entre 2014 y 2019, y caracterizar el perfil epidemiológico de los casos.

\section{MÉTODO}

Se realizó un estudio cuantitativo descriptivo, transversal y retrospectivo a través de datos del Sistema de Información de Enfermedades de Declaración Obligatoria (SINAN/SUS) del Departamento de Informática del Sistema Único de Salud (DATASUS). Los datos nacionales fueron recolectados de acuerdo con los siguientes pasos: Se accedió al enlace http://indicadoressifilis.aids.gov.br y en "Cobertura de datos" se seleccionaron "Datos regionales y nacionales" y en "Subcategoría" "Brasil". Se hizo clic en el botón "Descargar datos" y se eliminaron los datos relacionados con

Enlace de acceso: https://www.nucleodoconhecimento.com.br/salud/norte-de-brasil 
la sífilis congénita de Brasil. Posteriormente en "Cobertura de Datos" se seleccionó "Datos estatales" y en "Subcategoría" seleccionamos el nombre de cada estado de la región norte de Brasil, se descargaron las tablas de cada estado y se eliminó la información sobre sífilis congénita. Los datos se compilaron dentro de la aplicación Excel, un componente de la suite Microsoft Corporation Office.

\section{RESULTADOS}

El porcentaje de casos de sífilis congénita según el diagnóstico final por año de diagnóstico en Brasil entre 2014 y 2019 se muestra en la Tabla 1. Hubo un aumento en el porcentaje de casos del 12,28\% en 2014 al 18,21\% en 2019.

Tabla 1 - Muestra el porcentaje de casos de sífilis congénita según diagnóstico final por año de diagnóstico, en el norte de Brasil, entre 2014 y 2019.

\begin{tabular}{rrc}
\hline ANO & No CASOS & $\%$ \\
\hline $\mathbf{2 0 1 4}$ & 16353 & $12.28 \%$ \\
$\mathbf{2 0 1 5}$ & 19712 & $14.80 \%$ \\
$\mathbf{2 0 1 6}$ & 21330 & $16.01 \%$ \\
$\mathbf{2 0 1 7}$ & 25037 & $18.79 \%$ \\
$\mathbf{2 0 1 8}$ & 26531 & $19.92 \%$ \\
$\mathbf{2 0 1 9}$ & 24253 & $18.21 \%$ \\
\hline
\end{tabular}

En el norte de Brasil, el porcentaje de casos de sífilis congénita según el diagnóstico final por año de diagnóstico entre 2014 y 2019 fue de 11.071. En el período, hubo un aumento en el número de casos, de $11.13 \%$ en 2014 a $20.19 \%$ en 2019 (Figura 1). 
Figura 1 - Muestra el porcentaje de casos de sífilis congénita según diagnóstico final por año de diagnóstico, en el norte de Brasil, entre 2014 y 2019.

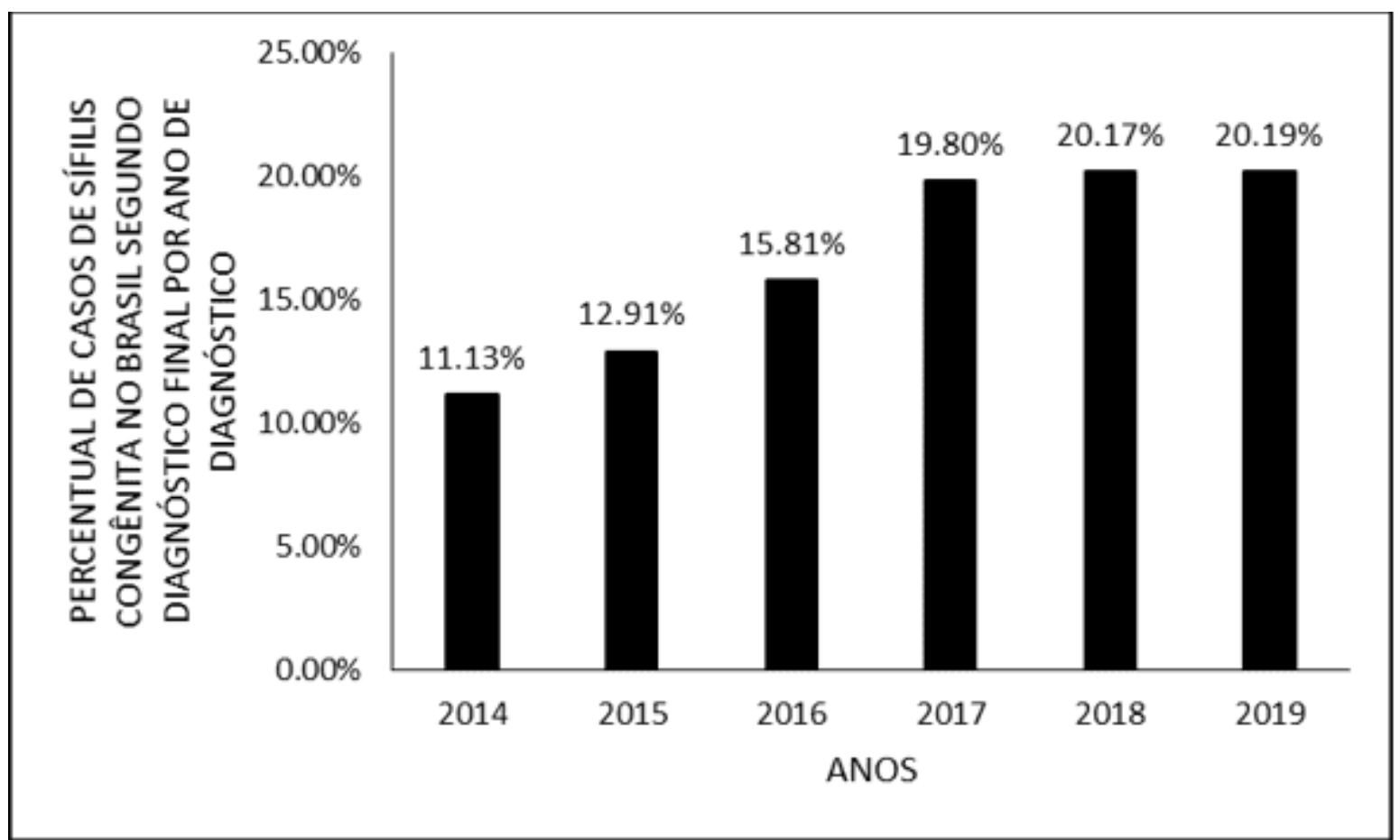

Entre los estados de la región Norte, Pará se destacó con el mayor número de casos $(42,08 \%)$ y el que con la menor cantidad, el estado de Roraima (1,83\%). (Figura 2$)$. 
Figura 2 - Muestra el porcentaje de casos de sífilis congénita según diagnóstico final por año de diagnóstico, por estado en la región Norte de Brasil, entre 2014 y 2019.

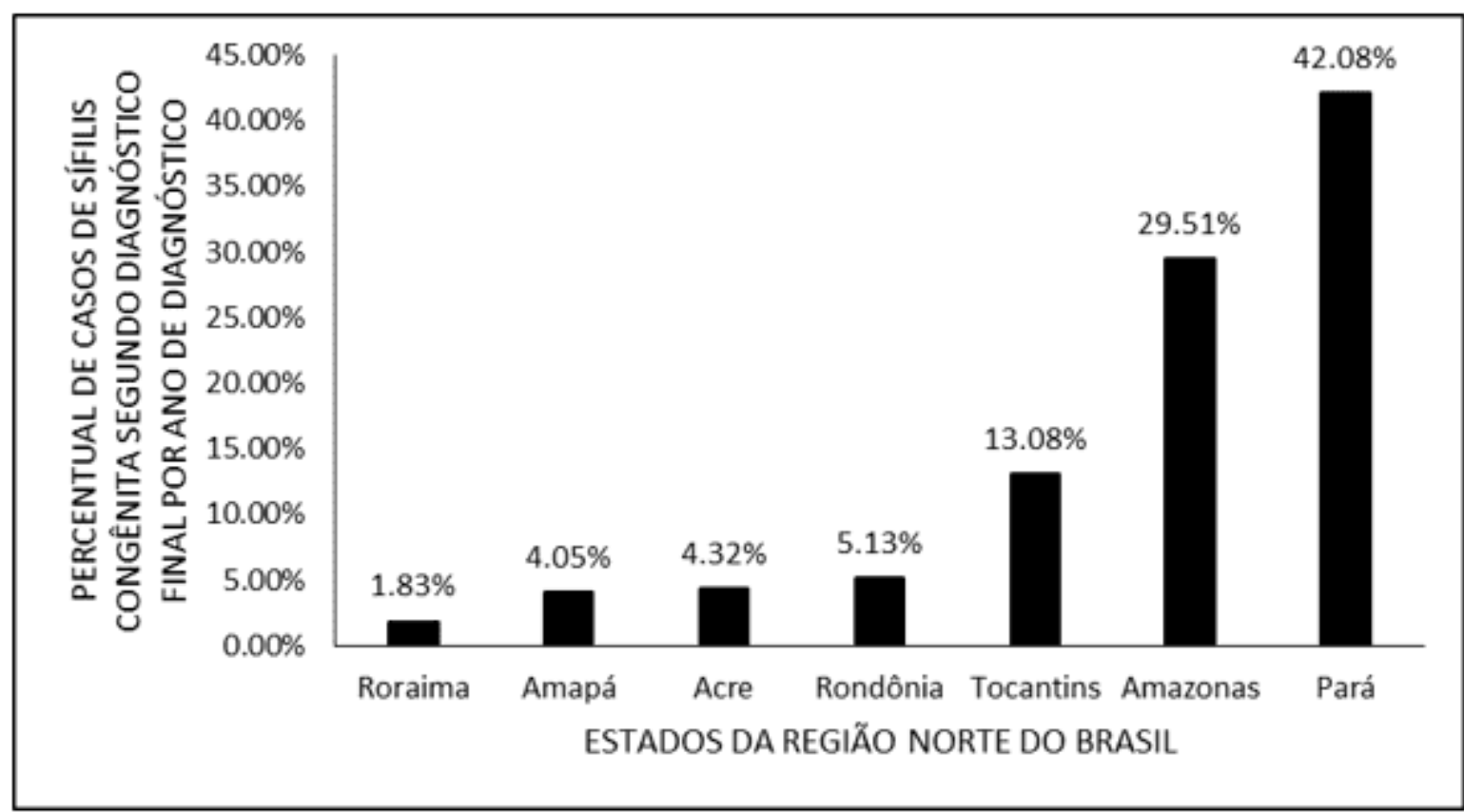

La Figura 3 muestra la distribución porcentual de los casos de sífilis congénita en la región Norte por segunda raza/color (etnia) entre 2014 y 2019. Los datos indican un mayor número de casos en el grupo étnico marrón con 9.638 (87,06\%), seguido de los blancos con 608 (5,49\%). Los grupos étnicos con el número más bajo fueron indígenas con $85(0,77 \%)$ y negros con $32(0,29 \%)$, respectivamente. 
Figura 3 - Muestra la distribución porcentual de los casos de sífilis congénita en la región Norte por segunda raza/color (etnia) entre los años 2014 y 2019.

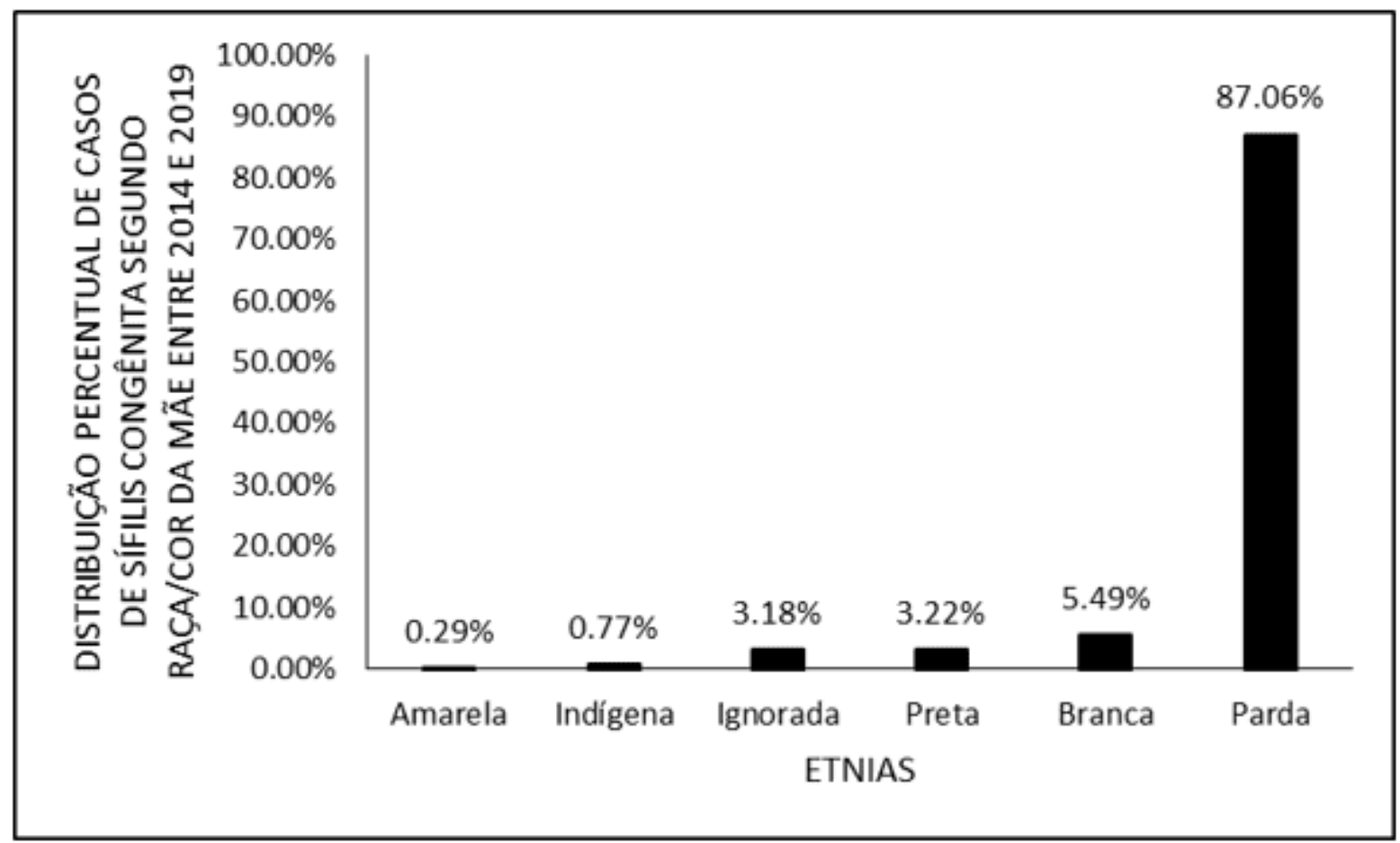

La Figura 4 muestra el número de casos confirmados de sífilis congénita en la región Norte por examen prenatal entre 2014 y 2019. Los datos muestran un mayor número de mujeres que se sometieron a atención prenatal 8.712 (78,69\%) que las que no se sometieron a $2.048(18,50 \%)$ y las consideradas ignoradas totalizaron $311(2,81 \%)$. 
Figura 4 - Muestra la distribución porcentual de los casos de sífilis congénita según la información sobre la atención prenatal de la madre por año de diagnóstico entre 2014 y 2019.

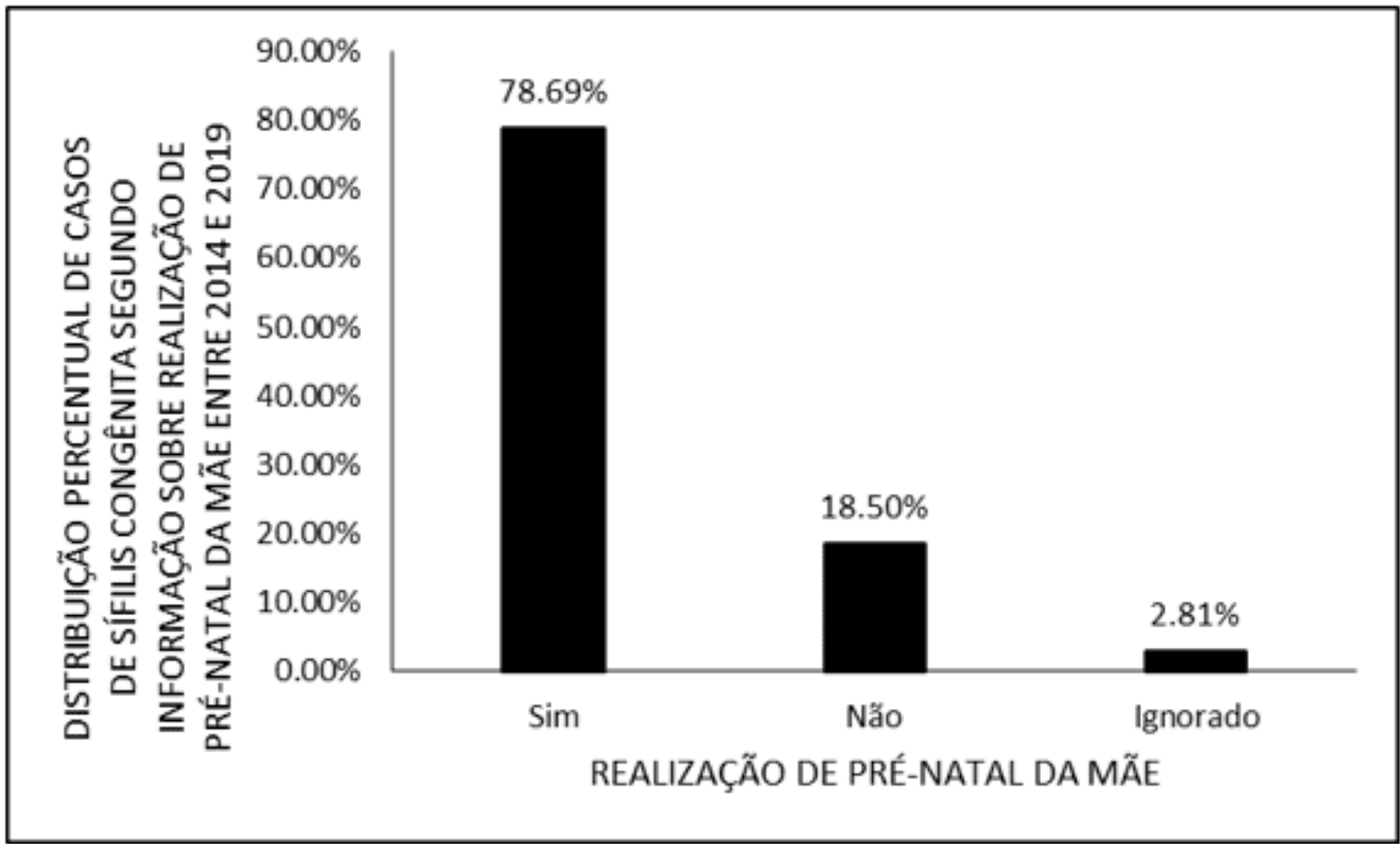

La Figura 5 muestra la distribución porcentual de los casos de sífilis congénita en la región Norte, según la escolaridad de la madre por año de diagnóstico entre 2014 y 2019. Los datos muestran un número importante de madres analfabetas de 62 mujeres $(0,90 \%)$, la mayoría de los casos con el grado escolar materno de la $5^{\underline{a}}$ a $8^{\mathrm{a}}$ escuela primaria incompleta con $2.362(33,80 \%)$, con una colección de mujeres que han completado la escuela primaria de $936(13,40 \%)$ y una parte completada la escuela secundaria 1.320 (18,90\%), el número más bajo de madres con educación superior completa fue de $62(0,90 \%)$ y el número de madres ignoradas fue de 2.243 $(32,10 \%)$. 
Figura 5 - Muestra la distribución porcentual de los casos de sífilis congénita en la región Norte, según la escolaridad de la madre por año de diagnóstico entre 2014 y 2019.

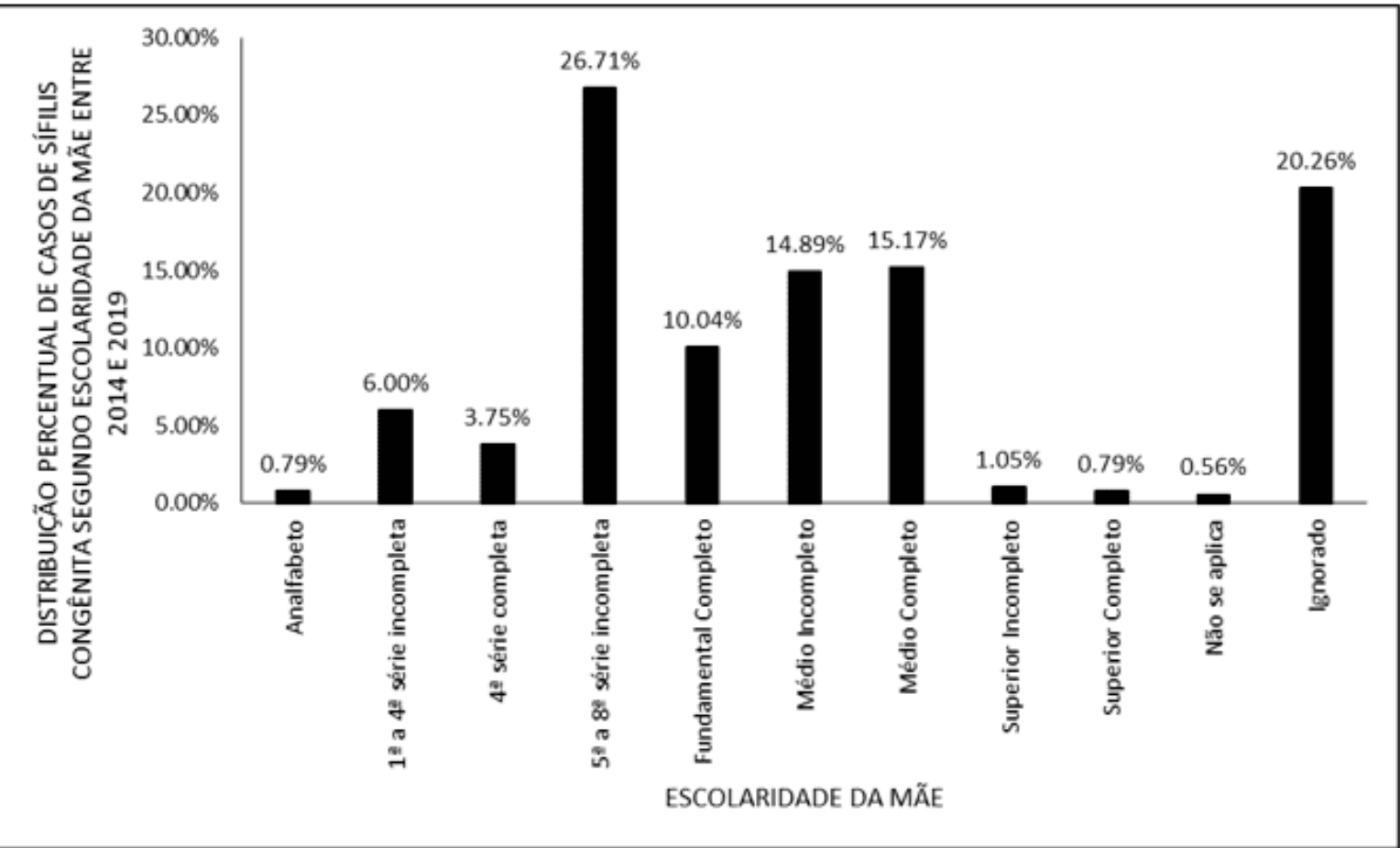

La Figura 6 muestra el número de casos confirmados de sífilis congénita en la región Norte en el momento del diagnóstico materno de sífilis, entre 2014 y 2019. Hay un mayor número de infecciones durante el examen prenatal con un número total de casos de $4.862(43,92 \%)$ y también en el momento del parto con $4.258(39,46 \%)$, con una minoría de casos diagnosticados en el período posparto, con un total de 1.388 $(12,54 \%)$ y los ignorados totalizaron $447(4,04 \%)$. 
Figura 6 - Muestra la distribución porcentual de los casos confirmados de sífilis congénita según el momento del diagnóstico en la región Norte, entre los años 2014 y 2019.

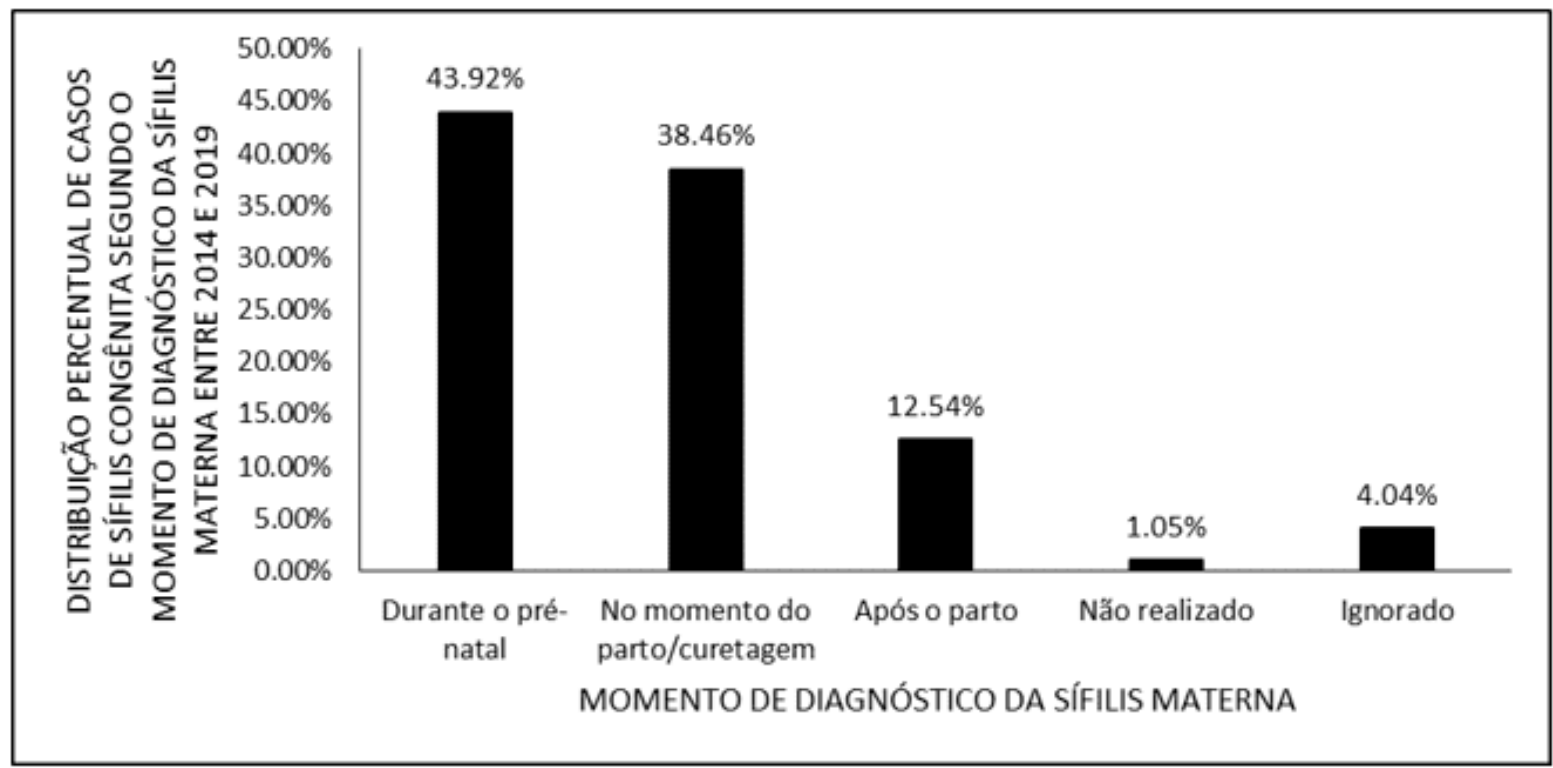

En cuanto a la clasificación final variable de la sífilis congénita, los datos encontrados fueron 10.475 (94,62\%) clasificados como sífilis congénita reciente; 24 clasificados como sífilis congénita tardía (0,22\%); $256(2,31 \%)$ abortos por sífilis; y $316(2,85 \%)$ nacidos muertos por sífilis (Tabla 2). 
Tabla 2 - Muestra la distribución porcentual de los casos de sífilis congénita según el diagnóstico final por año de diagnóstico, en la región Norte de Brasil, entre 2014 y 2019.

\begin{tabular}{c|c|c}
\cline { 2 - 3 } & $\begin{array}{c}\text { No CASOS } \\
\text { (2014 a 2019) }\end{array}$ & $\%$ \\
\hline $\begin{array}{c}\text { Sífilis congênita } \\
\text { recente }\end{array}$ & 10475 & $94.62 \%$ \\
Sífilis congênita tardia & 24 & $0.22 \%$ \\
Aborto por sífilis & 256 & $2.31 \%$ \\
Natimorto por sífilis & 316 & $2.85 \%$ \\
\hline
\end{tabular}

\section{DISCUSIÓN}

Hubo un aumento en el número de casos de 2014 a 2019 (figura 1), especialmente el Estado de Amazonas, que aumentó en un 416\% (figura 2) los registros de notificación de la enfermedad en el período observado, siendo incluso el Estado de la Región Norte con mayor PIB per cápita (IBGE, 2016). Este análisis de la relación entre la incidencia de la enfermedad y la capacidad económica del sitio se realiza por el hecho de que la sífilis congénita es una enfermedad diagnóstica relativamente fácil y es totalmente prevenible cuando el tratamiento de las mujeres embarazadas y la pareja se realiza adecuadamente (ARAUJO et al., 2006), lo que hace que su prevalencia se relacione generalmente con un poder económico deficiente para proporcionar una Salud Básica de calidad, más específicamente, para ofrecer una atención prenatal efectiva para la población (ARAUJO et al., 2006).

Sin embargo, el subdesarrollo no explicaría por sí solo la causa de que Amazonas sea el principal estado creciente de la enfermedad en el período observado, pues en comparación con otros estados de la Región Norte, es el mejor PIB, por lo que la mejora en la notificación de la enfermedad en el Estado, podría explicar el hecho de que la Región Norte tenga una alta prevalencia de esta comorbilidad. En 2016, el RC: 96424

Enlace de acceso: https://www.nucleodoconhecimento.com.br/salud/norte-de-brasil 
Departamento de Salud de Amazonas inició una campaña de descentralización para la realización de pruebas rápidas de enfermedades de transmisión sexual, previamente superconcentradas en FMT (Fundación de Medicina Tropical Heitor Vieira Dourado), redistribuyéndolas a los cuatro SAEs (Servicios de Atención Especializada) de la ciudad (BRASIL, 2016).

Aún en las perspectivas que buscan explicar la alta incidencia de sífilis congénita en la región Norte, el subdesarrollo también se relaciona con una población con un menor nivel de conciencia, es decir, no bastaría solo con la disponibilidad de atención prenatal, sino con la comprensión de la sociedad sobre la importancia de su realización, lo que ayuda a comprender por qué es un problema de salud pública aún tan presente en la Región Norte de Brasil, la segunda región brasileña con el PIB per cápita más bajo, solo superda por el Nordeste (IBGE, 2016).

En cuanto a la variable etnicidad en los casos registrados de sífilis congénita (figura 3 ), más del $90 \%$ de los casos fueron de etnia mixta (raza) que es también el grupo étnico más prevalente en la Región Norte, representando el 66,88\% de la población de esta región de Brasil (IBGE, 2010).

También es importante establecer un paralelismo con dos datos recogidos en la investigación, el porcentaje de madres infectadas que se sometieron a atención prenatal es superior al 70\% en el periodo observado (2014-2019) (figura 4), es decir, la mayoría de las mujeres de la región realizan este seguimiento, lo que debería implicar una menor incidencia de la enfermedad. Por otro lado, el número de parejas no tratadas es alto. La sífilis es una enfermedad de transmisión sexual, donde es obligatorio el tratamiento de la pareja. Esto refleja una difícil realidad de Brasil en la realización de una atención prenatal efectiva, la falta de seguimiento satisfactorio de la pareja en las consultas. Uno de los principales problemas que aún existe en el control de las infecciones de transmisión sexual (ITS) durante el embarazo es el abordaje de la pareja (DUARTE, 2007). Además, los problemas surgen con la notificación y continúan en un intento de convencerlos de la necesidad de un diagnóstico y tratamiento (DUARTE, 2007). 
Otro factor es el nivel de analfabetismo, solo el 0,9\% eran analfabetos y el porcentaje más alto es de personas que completaron al menos la escuela primaria (Figura 5). Sin embargo, alrededor del $8 \%$ de la población en el norte de Brasil es analfabeta, la segunda peor región, solo superda por la Región Nordeste (IBGE, 2019). Esta comparación de datos lleva a preguntas sobre el subregistro, si el mayor porcentaje de mujeres con sífilis en la región realmente tiene educación superior o si el porcentaje que busca atención y tiene los casos reportados es la mayoría instruida y la que tiene la educación más baja sigue sin buscar atención y no tiene la enfermedad reportada.

La atención prenatal inadecuada impide la rutina para el diagnóstico y el tratamiento efectivo y temprano (ARAUJO et al, 2006). Los datos sobre el momento del diagnóstico refuerzan la importancia de una atención prenatal efectiva para combatir la incidencia de sífilis congénita, ya que la mayoría tenía el diagnóstico en el parto o en el momento del legrado (Figura 6).

\section{CONCLUSIÓN}

Debido a la alta incidencia de casos de sífilis congénita, existe la prominencia de la región Norte en detrimento de otras regiones brasileñas. El subdesarrollo de la región es un factor fundamental para explicar este hecho, cuando hay un déficit en los sectores públicos, especialmente en educación y salud, la evidencia se refleja en la población. En relación a la Sífilis Congénita, la mayoría de las mujeres embarazadas tuvieron un bajo nivel de educación, dados estos datos, ante la falta de información sobre la importancia de la atención prenatal, tanto por la falta de interés de la población como por la poca difusión del sistema público de salud. Como ejemplo, el estado de Amazonas, que fue el estado con mayor porcentaje de casos reportados en el período analizado debido a un mayor desempeño en el tamizaje de infecciones de transmisión sexual, sin embargo, la mayor disponibilidad de métodos de tamizaje, exclusivamente, no es sinónimo de una mejoría en la incidencia de casos de Sífilis Congénita.

Además, el número de parejas no tratadas tiene gran relevancia, ya que la vía de transmisión más común de la sífilis es la vía sexual. Hay una falta de información y resistencia por parte de la mayoría de ellos. Por lo tanto, existe la necesidad de que RC: 96424

Enlace de acceso: https://www.nucleodoconhecimento.com.br/salud/norte-de-brasil 
la mujer embarazada junto con su pareja sean examinadas durante la atención prenatal para evitar una posible reinfección de un paciente tratado o un diagnóstico temprano.

Por lo tanto, se observa que para la reducción de la incidencia de casos de sífilis congénita, son necesarios una serie de factores, a partir de la mayor disponibilidad de información sobre la importancia de la atención prenatal y su continuidad por parte de las mujeres embarazadas y sus parejas. Por lo tanto, cubra el diagnóstico y tratamiento temprano, con el fin de evitar complicaciones para el feto o neonato.

\section{REFERENCIAS}

ARAUJO, Eliete da Cunha; Costa, Kelly de Souza Gama; SOUZA E SILVA, Rafaela; AZEVEDO, Valéria Nascimento; Lima, Fábio André Souto. Importância do pré-natal na prevenção da Sífilis Congênita. Revista Paraense de Medicina, Belém, v. 20, n. 1, p. 47-51, mar. 2006.2 Disponível em: http://scielo.iec.gov.br/scielo.php?script=sci arttext\&pid=S010159072006000100008\&lng=pt\&nrm=iso Acesso em: 24 maio 2019.

BARROS, Yara Lorrane Souza de. Et al. Numbers of confirmed syphilis cases in pregnant women in Brazil between 2009 and 2013. Revista Científica Multidisciplinar Núcleo do Conhecimento. Year 05, Ed. 11, Vol. 25, pp. 53-61. November 2020. ISSN:2448-0959, Access link in: https://www.nucleodoconhecimento.com.br/health/syphilis-cases, DOI: 10.32749/nucleodoconhecimento.com.br/health/syphilis-cases

BRASIL, Ministério da Saúde. Departamento de Doenças de Condições Crônicas e Infecções Sexualmente Transmissíveis: Manaus recebe apoio da ONG AHF para descentralizar 0 atendimento de HIV/aids. 2016. Disponível em: http://www.aids.gov.br/pt $\quad$ br/noticias/manaus-recebe-apoio-da-ong-ahf-paradescentralizar-o-atendimento-de-hivaids _ Acesso em: 23 maio 2019. 
BRASIL, Ministério da Saúde. Departamento de Vigilância, Prevenção e Controle das Infecções Sexualmente Transmissíveis, do HIV/Aids e das Hepatites Virais: Protocolo Clínico e Diretrizes Terapêuticas para Atenção Integral às Pessoas com Infecções Sexualmente Transmissíveis (IST). 2018. Disponível em: http://conitec.gov.br/images/Artigos Publicacoes/Diretrizes/PCDT Atencao Integral IST 22-10-18.pdf Acesso em: 23 maio 2019.

CARDOSO, Ana Rita Paulo; ARAÚJO, Maria Alix Leite; CAVALCANTE, Maria do Socorro; FROTA, Mirna Albuquerque; DE MELO, Simone Paes. Análise dos casos de sífilis gestacional e congênita nos anos de 2008 a 2010 em Fortaleza, Ceará, Brasil. Ciência \& Saúde Coletiva. v. 23, n. 2, p. 563-574, 2018. Disponível em: https://www.scielosp.org/article/csc/2018.v23n2/563-574/ Acesso em: 24 maio 2019.

CAVALCANTE, Ana Egliny S; SILVA, Maria Adelane M; RODRIGUES, Antonia Regynara M; NETTO, José Jeová Mourão; MOREIRA, Andréa CA; GOYANNA, Natália F. Diagnóstico e tratamento da sífilis: uma investigação com mulheres assistidas na atenção básica em Sobral, Ceará. DST Jornal Brasileiro de Doenças Sexuais. v. 24, n. 4, p. 245-245, 2012. Disponível em: http://www.dst.uff.br/revista244-2012/4-Diagnostico\%20e\%20Tratamento\%20da \%20Sifilis.pdf Acesso em: 23 maio 2019.

CAVAlCANTE, Patricia Alves de Mendonça; PEREIRA, Ruth Bernardes de Lima; CASTRO, Jose Gerley Diaz. Sífilis gestacional e congênita em Palmas, Tocantins, 2007-2014. Epidemiologia e Serviços de Saúde. v. 26, n. 2, p. 255-264, abr.jun, 2017. Disponível em: https://www.scielosp.org/article/ress/2017.v26n2/255264/pt/ Acesso em: 23 maio 2019.

CRT. Centro de Referência e Treinamento DST/AIDS-SP. Coordenadoria de Controle de Doença, Secretaria de Estado da Saúde de São Paulo (SES-SP). Guia de bolso para o manejo de sífilis em gestante e sífilis congênita. 2 ed., 112 p. São Paulo: Secretaria de Estado da Saúde. 2016. Disponível em: http://www.saude.campinas.sp.gov.br/saude/doencas/sifilis/guiadebolsodasifilis_2edi cao2016.pdf Acesso em: 23 maio 2019.

Enlace de acceso: https://www.nucleodoconhecimento.com.br/salud/norte-de-brasil 
DUARTE, Geraldo. Extensão da Assistência Pré-natal ao Parceiro como Estratégia de Aumento da adesão ao Pré-natal e Redução da Transmissão Vertical de Infecções. Revista Brasileira de Ginecologia e Obstetrícia. v. 29, n. 4, p. 171-174, 2007.

GUINSBURG, Ruth; SANTOS, Amélia Miyashiro Nunes dos Santos. Critérios diagnósticos e tratamento da sífilis congênita. Documento científico Departamento de Neonatologia. São Paulo: Sociedade Brasileira de Pediatria. 2010.

https://www.sbp.com.br/fileadmin/user upload/2015/02/tratamento sifilis.pdf Acesso em: 24 maio 2019.

Instituto Brasileiro de Geografia e Estatística (IBGE). Contas regionais do Brasil: 2010-2014, Coordenação de Contas Nacionais. - Rio de Janeiro: IBGE, 2016. 97 p. (Contas nacionais, ISSN 1415-9813; n. 53). Disponível em: https://biblioteca.ibge.gov.br/visualizacao/livros/liv98881.pdf Acesso em: 24 maio 2019.

Instituto Brasileiro de Geografia e Estatística (IBGE), Diretoria de Pesquisas, Coordenação de Trabalho e Rendimento, Pesquisa Nacional por Amostra de Domicílios Contínua 2016-2018. 2019. Disponível em: https://biblioteca.ibge.gov.br/visualizacao/livros/liv101657_informativo.pdf Acesso em: 24 maio 2019.

IBGE. Instituto Brasileiro de Geografia e Estatística. Sistema IBGE de Recuperação Automática - $\quad$ SIDRA. $2010 . \quad$ Disponível em: https://sidra.ibge.gov.br/Tabela/3175\#resultado Acesso em: 24 maio 2019.

MOTTA, Isabella almeida; DELFINO, Isabella Rey de Souza; DOS SANTOS, Leticia Vettorazzi; MORITA, Maura Omori; GOMES, Rayanne Gonçalves Dantas; MARTINS, Talita Pouzas Soares; CARELLOS, Ericka Vianna Machado; ROMANELLI, Roberta Maia de Castro. Sífilis congênita: por que sua prevalência continua tão alta?. Revista Médica de Minas Gerais, Belo Horizonte, v. 28. Suppl. 6, 2018. Disponível em: http://rmmg.org/artigo/detalhes/2418 Acesso em: 23 maio 2019.

Enlace de acceso: https://www.nucleodoconhecimento.com.br/salud/norte-de-brasil 
ROCHA, Karina Dias. Et al. Number of congenital syphilis cases in Brazil between 2009 and Revista Científica Multidisciplinar Núcleo do Conhecimento. Year 05, Ed. 05, Vol. 01, pp. 131-143. May 2020. ISSN:2448-0959 DOI: 10.32749/nucleodoconhecimento.com.br/health/congenital-syphilis-cases

Enviado: Diciembre de 2020.

Aprobado: Diciembre de 2020. 